\title{
Burned or engaged teachers? The role of mindfulness, self-efficacy, teacher and students' relationships, and the mediating role of intrapersonal and interpersonal mindfulness
}

\author{
Nieves Moyano ${ }^{1} \cdot$ Maria C. Perez-Yus $^{2,3}$ (D) $\cdot$ Paola Herrera-Mercadal ${ }^{3,4} \cdot$ Mayte Navarro-Gil $^{2,3} \cdot$ Sandra Valle $^{4}$. \\ Jesus Montero-Marin ${ }^{5}$
}

Accepted: 24 October 2021

(C) The Author(s) 2021, corrected publication 2022

\begin{abstract}
This study had the goal to examine factors that are associated with burnout and engagement among teachers from diverse educational stages. Among these factors, we analyzed socio-demographic aspects, such as gender, age and years of experience, and other psychological teacher-related variables like teacher's self-efficacy and teacher-student relationships. We also considered the potential mediating role of mindfulness in these relationships. The sample was made up by 425 Spanish teachers who answered an online survey. We administered the following measures: Revised version of the Teacher's Burnout Questionnaire, Utrecht Work Engagement Scale, Mindfulness in Teaching Scale -which distinguished between intrapersonal and interpersonal mindfulness-, Teacher's Sense of Self-efficacy Scale, and some questions related to the relationships between students and teachers in the classroom. We conducted a mediational analysis through structural equation modeling (SEM). Our findings indicated that both intrapersonal and interpersonal mindfulness mediated the relation between self-efficacy, which played a direct and an indirect role, the teacher-student relationship, and burnout and engagement. The socio-demographic variables of gender and years of experience played a significant role in mindfulness. The teachers with more self-efficacy were more likely to pay attention to their daily activity and to show more receptivity with their students, which resulted in lower burnout and more engagement. In addition, better relationships with students led to higher intrapersonal mindfulness levels, which mediated the relation with burnout and engagement. These relations varied depending on specific burnout and engagement dimensions. We discuss the implications of these findings for improving teachers' implication in the education field.
\end{abstract}

Keywords Burnout $\cdot$ Engagement $\cdot$ Mindfulness $\cdot$ Teaching $\cdot$ Self-efficacy $\cdot$ Teacher-student relationship

Mindfulness is defined as the ability to pay attention to the present moment intentionally and without judging

Maria C. Perez-Yus

mcperezy@unizar.es

1 Faculty of Humanities and Science Education, University of Jaén, Andalusia, Jaén, Spain

2 School of Educación, University of Zaragoza, Zaragoza, Spain

3 Aragon Health Research Institute, IIS, Zaragoza, Aragón, Spain

4 School of Human Sciences and Education, University of Zaragoza, Huesca, Spain

5 Department of Psychiatry, Warneford Hospital, University of Oxford, Oxford OX3 7JX, England experience (Kabat-Zinn, 1994). In the educational field, different reviews indicate the potential of mindfulness as a mechanism for alleviating some mental and physical disorders, such as anxiety, depression, stress, clinical pain, etc. (Mochrie et al., 2019; Montero-Marin et al., 2021; Roeser et al. 2012, 2012). Teaching is a challenging profession that unfolds in a growing students' diversity and complex competitive world, involving high social demands and pressure in education (Kyriacou, 2001; Roeser et al., 2013). However, to date most research on mindfulness has focused on students, and has often neglected teachers (Heineberg, 2016). Prevalence of stress, burnout, depression, and anxiety, or low self-esteem, among teachers is high which can, in turn, affect students (Gold et al. 2010; Meiklejohn et al. 2012; Napoli 2004; Roeser et al. 2012). 
Burnout has been recently included in the 11th Revision of the International Classification of Diseases (ICD-11) as an occupational phenomenon by the World Health Organization (WHO 2019). It has been defined as "a syndrome of emotional exhaustion, depersonalization, and reduced personal accomplishment which is a special risk for individuals who work with other people in some capacity" (Leiter and Maslach 1998). According to the WHO (2019), this syndrome refers "specifically to phenomena in the occupational context and should not be applied to describe experiences in other areas of life". The most frequent cause is prolonged stress (Bakker and Demerouti 2007). To date, burnout syndrome has been explored among several jobs, mainly related to health, education, and those who take care for others (García-Carmona et al. 2019; Kim et al. 2019; López-López et al. 2019; Tawfik et al. 2019). Teaching is a context in which prevalence of burnout is high (Durán et al. 2005; Küster and Vila 2012; Tifner et al. 2006). Some of the reasons, as indicated by Esteras et al. (2014), is because teaching is a very vocational job, which requires a large amount of personal and emotional involvement. School is an scenario in which teachers have to cope with several difficulties, which sometimes lead them to stress due to lack of adequate strategies or skills (Arias and González 2009; Calvete 2010; Díaz et al. 2012; Gantiva et al. 2010; Guerrero et al., 2011). Some models have been proposed to explain the origins of burnout, such as the "transactional model of stress and coping" (Lazarus and Folkman, 1984), or the "job demands-resources model" (Demerouti et al. 2001). Central to these models is the assumption that job stressors require the prolonged exertion of physical, psychological or emotional effort, which causes stress when someone's resources are exceeded (Aldrup et al. 2018).

Mindfulness has consistently been related to low burnout (Abenavoli et al. 2013; Flook et al. 2013; Roeser et al. 2013; Taylor and Millear 2016). The "job demands-resources model" of burnout (Bakker and Demerouti 2007) has been proposed to explain the enhancer role of mindfulness (Taylor and Millear 2016). According to this model, burnout emerges when workers perceive that the quality and quantity of the demands in the workplace exceed the quality and quantity of the resources they have available. This model opens the door insofar as the highly demanding teaching context and subsequent burnout development are mediated by the resources that can be either environmental or personal. Hence mindfulness has been suggested as one of these personal traits that could be protective (Taylor and Millear 2016).

Some of the strategies teachers need to cope with burnout are related to self-efficacy, which is defined as the belief that teachers have about their own abilities to influence satisfactory academic results among their students (TschannenMoran et al., 2001). It has been found that teachers with high self-efficacy display greater engagement and enthusiasm with their students to teach (Allinder 1994; Coladarci 1992), show more job satisfaction (Caprara et al., 2003; Judge et al. 2001), spend more time planning and organizing their classes (Allinder 1994), and are better inclined to implement new learning methods and strategies (Stein and Wang, 1988). A growing consensus has been reached about the relation between self-efficacy and burnout (Brouwers and Tomic, 2000; Evers et al. 2002; Schwarzer and Hallum, 2008; Shoji et al. 2016; Skaalvik and Skaalvik 2010). The longitudinal study of Brouwers and Tomic (2000) suggested that teachers who distrust their classroom management abilities under standard job conditions, among other factors, can easily suffer stress and exhaustion, and take negative attitudes. Therefore, improving the self-efficacy of teachers can be vital for achieving more efficient schools (Savaş et al. 2014).

Teacher-student relationships have been linked with positive students' cognitive and affective outcomes, such as participation, critical thinking, satisfaction, math achievement, drop-out prevention, self-esteem, verbal achievement, positive motivation, social connection, IQ, grades, reduction in disruptive behavior, attendance, perceived achievement, peer students' sociometric nominations, internalizing and externalizing behavioral problems, among others (Baker et al. 2008; Cornelius-White 2007; Hughes et al. 2001; Wubbels and Brekelmans 2005). Teacher-student relationships have also been recently linked to burnout (Aldrup et al. 2018; Corbin et al. 2019; Taxer et al. 2019). In a study by Corbin et al. (2019), applying the Lazarus' "transactional model of stress and coping", stress derives from transactions between the teacher and the information provided by the classroom environment, which is assessed by teachers in a two-stage appraisal. Stress and subsequent burnout emerge when the evaluation made by teachers in the first appraisal is relevant and incongruent, and when teachers judge their coping abilities as insufficient in the second appraisal. Good teacherstudent relationships are evaluated as relevant and congruent with teachers' aims and, hence, interrupt the stress generating process. When teachers perceive bad relationships with their students as being relevant and incongruent with their goals, they perceive themselves as being unable to cope. This results in stress which, if sustained in time, will turn into burnout. The study of teacher-student relationships has focused mostly on student outcomes (Spilt et al. 2011). However, according to these authors, teachers have a basic psychological need for relatedness with their students, and these experiences can affect teacher well-being in the long term.

Along with the study of burnout, the literature also reflects a novel focus of analysis resulting from an approach marked by positive psychology, which focuses on human strengths and human beings' optimal functioning (Seligman and Csikszentmihalyi 2014). In this research line, we find the "work engagement", concept, which was 
initially described by Maslach (1997) as a "positive state characterized by presenting a high energy load, involvement and professional efficiency". The concept of engagement represents a new approach that examines the positive experiences of workers and the favorable conditions of well-being, and has been defined as a positive and persistent motivating state related to work and integrated by the dimensions of vigor, dedication and absorption (Salanova et al., 2005; Schaufeli et al. 2002). Mindfulness, selfefficacy and teacher-student relationships have shown the potential for managing both burnout and engagement (Betoret 2006; Braun 2019; Emerson et al. 2017; Flook et al. 2013; Mojsa-Kaja et al. 2015). Previous studies suggest that self-efficacy and mindfulness significantly correlate (Özcan \& Vural, 2020), and better teacher-student relationships would favor teachers' receptivity to their students' needs (Milatz et al., 2015; Skaalvik and Skaalvik 2010). Previous research has also found mediating effects of mindfulness on burnout (Merdiaty \& Aldrin, 2020) and engagement (Kotzé \& Nel, 2016). In the latter study, mindfulness was evaluated using short versions of the "mindful attention awareness scale" (MAAS), and "Freiburg mindfulness inventory" (FMI) questionnaires. The MAAS questionnaire came over as a significant predictor of burnout, and both the MAAS and the FMI were significant for engagement. Given the mediating effect of mindfulness on burnout and engagement, studying how mindfulness could potentially mediate the relationships between self-efficacy and teacher-student relationships, and burnout and engagement in the teaching environment, is interesting.

Furthermore, mindfulness in teaching has been recently defined by two different dimensions, intrapersonal and interpersonal mindfulness, as measured by the "mindfulness in teaching scale" (MTS) (Frank et al., 2016). Intrapersonal mindfulness is aligned with the present moment to reach complete consciousness, and includes items that reflect awareness, attention, and being in the present moment. Interpersonal mindfulness includes items that represent an open disposition and approach with acceptance and receptiveness in teacher-student interactions. Further research needs to determine whether these two factors of mindfulness in teaching recently proposed can predict differential outcomes.

In this context, the main goal of the present study was to analyze the potential mediating role of mindfulness (e.g., intrapersonal and interpersonal) in the relation among sociodemographic variables (e.g., gender, age, and years of experience), teachers' self-efficacy, relationships with students, and burnout and engagement. Using structural equation modeling (SEM), we explored if self-efficacy and relationships with students predicted both intrapersonal and interpersonal mindfulness $(\mathrm{H} 1)$, and if both intrapersonal and interpersonal mindfulness could act as mediators for burnout and engagement $(\mathrm{H} 2)$.

\section{Method}

\section{Participants}

In this study, 425 teachers were recruited. No missing data were found in more than $25 \%$ of the survey and, therefore, no cases were eliminated. The sample comprised $32 \%$ men and $68 \%$ women. All of them were Spanish and their age ranged between 25 and 69 years old $(M=44.14 ; S D=10.16)$. Regarding marital status, most of the participants were married $(54.8 \%)$, or single $(27.1 \%)$. The majority of participants had children (66.5\%). All the participants were actively involved in teaching activities - with their mean teaching years being about 16 years $(S D=10.52)$ - in different education stages (20.4\% Pre-School, 29.9\% Primary, $35.9 \%$ Secondary and $21.7 \%$ University Education, with a remaining 9\% for Vocational Training, and 3.5\% others), from both public and state-assisted education institutions in several Spanish Autonomous Communities (Aragon, Catalonia, Madrid and the Valencian Community). Their maximum level of education was mostly graduate $(57.8 \%)$, their type of contract was mainly permanent (65\% vs. temporary $34 \%$ ), teaching was a fulltime activity (83\%), and their main activities were related to "teaching" (64.2\%). The remaining percentage was about performing some management and/or research tasks.

\section{Procedure}

All the self-reported measures were built on an online survey. A search for publicly accessible emails from the educational environment and teachers' work, such as schools, colleges, blogs and existing Facebook pages, was made. To obtain an adequate response rate, many centers and subjects were contacted, and sent a link to access questionnaires. When clicking the link, participants were first allowed to access the study information and informed consent, and indicate "yes" before being directed to all the questionnaires. No code or identification system was required for the participants as questionnaires had to be completed at once, which favored their anonymity. The research was approved by the Research Ethics Committee of the Spanish Autonomous Community of Aragon: CEICA (No. 08/2019; April 24, 2019), which is in charge of evaluating all research projects with people or personal data from the University of BLINDED.

\section{Measures}

Socio-demographic data regarding participants' gender, age (in years), nationality, city of residence, marital status 
(single, married, cohabiting couple, separated/divorced, widowed, other), if they had children (yes/no), maximum level of education (graduate/bachelor's/diploma, master's, doctorate, others), stage of education they taught (PreSchool, Primary, Secondary and University Education), years of experience in the teaching field, job occupancy (part-/full-time), type of contract (temporary/permanent), and tasks performed (teaching, management/administration, research, other) were collected.

Teacher-Student Relationships This scale has been used in several national Spanish studies that have analyzed the relationship between students and teachers (Díaz-Aguado Jalón et al., 2013). In the present study, we used the following five items: "Students do not respect me", "Students disregard me" "Students offend me", "Students confront me" and "Students insult me". They all reflect situations in which students offend and disrespect the teacher. Responses reflect the frequency of the referred behaviors in the last 2 months of class. It uses a 4-point Likert-type scale, where 1 means "never" (I have not suffered it), 2 "sometimes" (once or twice a month", 3 "often" (approximately once a week), and 4 "many times" (several times a week). A total score is calculated to obtain an overall score indicative of negative teacher-student relationships. Therefore, higher scores indicate negative teacher-student relationships. The model fit of the Teacher-student relationships scale measurement model in the present study using a confirmatory factor analysis (CFA) was: $\chi^{2}=3.56 ; d f=3 ; \chi^{2} / d f=1.18$, RMSEA $(90 \%$ $\mathrm{CI})=0.02(0.01-0.03) ; \mathrm{SRMR}=0.02 ; \mathrm{CFI}=.99 ; \mathrm{TLI}=.99$. The internal consistency for this scale in the present study was $\omega=0.82$.

Teacher Sense of Self-Efficacy Scale (TSES; Tschannen-Moran et al., 2001) The TSES is a 24-item scale that assesses teachers' perception of self-efficacy; that is, the degree to which teachers believe that they are qualified to maintain control over students in the classroom. It is formed by three dimensions, each combining four items: use of strategies in the classroom (e.g., "To what extent can you use a variety of assessment strategies?); classroom management (e.g., "To what extent can you control misbehavior in class?"); student engagement (e.g., "To what extent do you feel able to motivate those students who show little interest in school work?"). Items are answered on a 9-point Likert-type scale (from $1=$ "not at all", to 9= "absolutely"). In the present study, a global score was used, with higher scores indicating a higher sense of self-efficacy. The measurement model fit indices using CFA were as follows: $\chi^{2}=503.81$; $d f=241 ; \chi^{2} / d f=2.08$, RMSEA $(90 \% \mathrm{CI})=0.05(0.04-0.06)$; $\mathrm{SRMR}=0.05 ; \mathrm{CFI}=0.93 ; \mathrm{TLI}=0.92$. The internal consistency for the general factor was $\omega=0.89$. In the present study, the Spanish version of the TSES (Burgueño and Sicilia, 2018) was used.

Mindfulness in Teaching Scale (MTS; Frank et al. 2016) We used the validated Spanish version from Moyano et al. (2021). It consists of a self-reported measure that assesses how teachers focus on daily activities, emotions, sensitization, self-regulation and responsibility, and includes 14 items answered on a 5-point Likert-type scale (from 1 = "never", to 5 = "always"). It has two dimensions: the intrapersonal dimension, which is related to attentional experience directed at oneself (e.g., "When I am teaching it seems I am running on automatically without being well aware of what I am doing"), and the interpersonal dimension, which requires the capacity of empathy and receptivity in relationships with students (e.g., "listening and fully paying attention to others" or "being receptive to others' demands"). The intrapersonal dimension items were inverted insofar as higher scores indicated higher levels of mindfulness, similarly to the interpersonal dimension. The model fit of the MTS in the present study using CFA was: $\chi^{2}=151.00 ; d f=72 ; \chi^{2}=3.56 ; d f=3$; $\chi^{2} / \mathrm{df}=2.10$, RMSEA $(90 \% \mathrm{CI})=0.05 ; \mathrm{SRMR}=0.04$; $\mathrm{CFI}=0.94 ; \mathrm{TLI}=0.92$. The internal consistency for intrapersonal mindfulness was $\omega=0.81$, and it was $\omega=0.70$ for interpersonal mindfulness.

The Revised Version of the Burnout Teachers Questionnaire - Cuestionario de Burnout en Profesorado-Revisado (CBP-R; Moreno Jiménez et al., 2000) It is a parallel questionnaire that derives from the Maslach Burnout Inventory (Maslach and Jackson 1981), but is specific for analyzing burnout in the teaching profession. It comprises 16 items and consists of three dimensions: emotional exhaustion (e.g., "I feel emotionally drained by my work"), depersonalization (e.g., "I just want to do my work and not be bothered"), and personal accomplishment (e.g., "In my opinion, I am very good at doing my job"). Higher scores indicate higher burnout levels, except for "personal accomplishment", for which higher scores indicate lower burnout levels. The CBP-R is answered on a 7-point Likert-type scale (from $0=$ "never", to $6=$ "every day"). The model fit of the CBP-R in the present study using CFA was: $\chi^{2}=221.15$; $d f=97 ; \chi^{2} / d f=2.28$, RMSEA $(90 \% \mathrm{CI})=0.06(0.05-0.07)$; $\mathrm{SRMR}=0.05 ; \mathrm{CFI}=0.96 ; \mathrm{TLI}=0.95$. The internal consistency in the present study was $\omega=0.90$ for emotional exhaustion, $\omega=0.84$ for depersonalization and $\omega=0.87$ for personal accomplishment.

Utrecht Work Engagement Scale (UWES; Schaufeli et al. 2006) The short Spanish 9-item version of the UWES was used (Serrano et al. 2019). It is a scale that analyzes engagement; that is, the degree of commitment to their work. It is composed of three subscales: vigor (e.g., "At my job, 
I feel strong and vigorous"), dedication (e.g., "I find the work that I do full of meaning and purpose"), and absorption (e.g., "When I am working, I forget everything else around me"), with items following a 7-point Likert-type scale (from $1=$ "never" to $7=$ "always"). The higher the score, the higher the degree of engagement. The model fit of the UWES in the present study using CFA was: $\chi^{2}=41.75$; $d f=20 ; \chi^{2} / \mathrm{df}=2.09$, RMSEA $(90 \% \mathrm{CI})=0.05(0.03-0.07)$; $\mathrm{SRMR}=0.02 ; \mathrm{CFI}=0.99 ; \mathrm{TLI}=0.98$. In the present study, internal consistency was $\omega=0.86$ for vigor, $\omega=0.92$ for dedication and $\omega=0.80$ for absorption.

\section{Statistical Analysis}

First, descriptive statistics were obtained for all the sociodemographic data and psychological variables that were evaluated using means (standard deviations) and frequencies (percentages) depending on the distribution of each variable. We also examined whether there were significant differences in the psychological variables for the education stage that the participants had to teach. For that, we conducted a MANOVA to compare teaching in three stages: Pre-School and Primary (together), Secondary, and University Education.

Subsequently, the relation between some socio-demographic variables (gender, age, and years of experience) and the corresponding dimensions of the psychological variables were analyzed by Pearson correlations (the point-biserial correlation was used for gender). The global scores obtained in self-efficacy and teacher-student relationships were used. For mindfulness, the considered dimensions were intrapersonal and interpersonal; for engagement they were vigor, dedication and absorption; for burnout, they were emotional exhaustion, depersonalization and personal accomplishment.

In order to test the potential mediating role of both intrapersonal and interpersonal mindfulness to explain the relation among socio-demographic variables (gender, age, and years of experience), self-efficacy, relationships with students, and burnout and engagement, a SEM approach was performed using Mplus 8.6. It was estimated with the Robust Maximum Likelihood (MLR) method, which provides tests of model fit and standard errors that are robust to nonnormality violations of data, and can be used for Likert-type scales (Rhemtulla et al., 2012). Model assessment was based on the following goodness-of-fit indices: Chi-squared/degrees of freedom $\left(\chi^{2} / d f\right)$, root mean square error of approximation (RMSEA), standardized root mean square residual (SRMR), comparative fit index (CFI), and Tucker-Lewis Index (TLI). $\chi^{2}$ is very sensitive to sample size, so we used $\chi^{2} / d f$, which indicates a good fit when $<5$ and an excellent fit if $<3$ (Hu \& Bentler, 1999; Schermelleh-Engel et al., 2003). Values of 0.08 and of 0.06 or less for RMSEA and SRMR are considered adequate and excellent, respectively (Marsh et al., 2004). Higher values of 0.90 and 0.95 for CFI and TLI indicate adequate and excellent fit, respectively (Marsh et al., 2004). Standardized regression weights $(\beta)$ and explained variance $\left(\mathrm{R}^{2}\right)$ were reported. All the tests used were bilateral and the significance level was $\alpha<0.05$.

\section{Results}

As observed in Table 1, and according to the possible range of each scale, the levels of emotional exhaustion and depersonalization were low, in contrast to the scores obtained in personal achievement. The scores of both intrapersonal and interpersonal mindfulness were moderate-slightly high because they lie at the theoretical midpoint of the scale. The self-efficacy and engagement levels on all its three dimensions were also high. Finally, the (problematic) relationship with students' scores were in the minimum range. No significant differences were found for any variable in terms of the educational stage of participants: Exhaustion $\left(F_{(3,375)}=.18\right.$, $p=.90)$, Depersonalization $\left(F_{(3,375)}=.82, p=.48\right), \mathrm{P}$. Accomplishment $\left(F_{(3,375)}=.96, p=.41\right)$, Intrapersonal mindfulness $\left(F_{(3,375)}=.1 .88, p=.13\right)$, Interpersonal mindfulness $\left(F_{(3,375)}=.08, p=.96\right)$, Self-efficacy $\left(F_{(3,375)}=.79\right.$, $p=.49)$, Relationship with students $\left(F_{(3,375)}=.51, p=.67\right)$, Vigor $\left(F_{(3,375)}=.51, p=.67\right)$, Dedication $\left(F_{(3,375)}=.43\right.$, $p=.73)$ and Absorption $\left(F_{(3,375)}=.44, p=.72\right)$.

Raw correlations between the examined variables are shown in Table 2. The socio-demographic variables were scarcely related to the psychological variables under study. Only years of experience significantly and negatively correlated with intrapersonal mindfulness. There were significant correlations among all the psychological variables analyzed, except between emotional exhaustion and interpersonal mindfulness, between personal accomplishment and

Table 1 Descriptive statistics of the examined variables

\begin{tabular}{llll}
\hline & Range & $M$ & $S D$ \\
\hline Emotional Exhaustion & $0-30$ & 8.73 & 5.48 \\
Depersonalization & $0-30$ & 6.20 & 5.55 \\
Personal Accomplishment & $0-36$ & 26.26 & 6.32 \\
Intrapersonal Mindfulness & $10-45$ & 36.85 & 5.00 \\
Interpersonal Mindfulness & $7-25$ & 19.71 & 3.27 \\
Self-efficacy & $81-216$ & 167.15 & 22.09 \\
Vigor & $3-21$ & 16.61 & 3.31 \\
Dedication & $3-21$ & 16.62 & 3.67 \\
Absorption & $3-21$ & 17.63 & 3.09 \\
Relationship with students* & $5-20$ & 5.88 & 1.52 \\
\hline
\end{tabular}

*"Problematic" relationships with students. $\mathrm{M}=$ mean. $\mathrm{SD}=$ standard deviation 


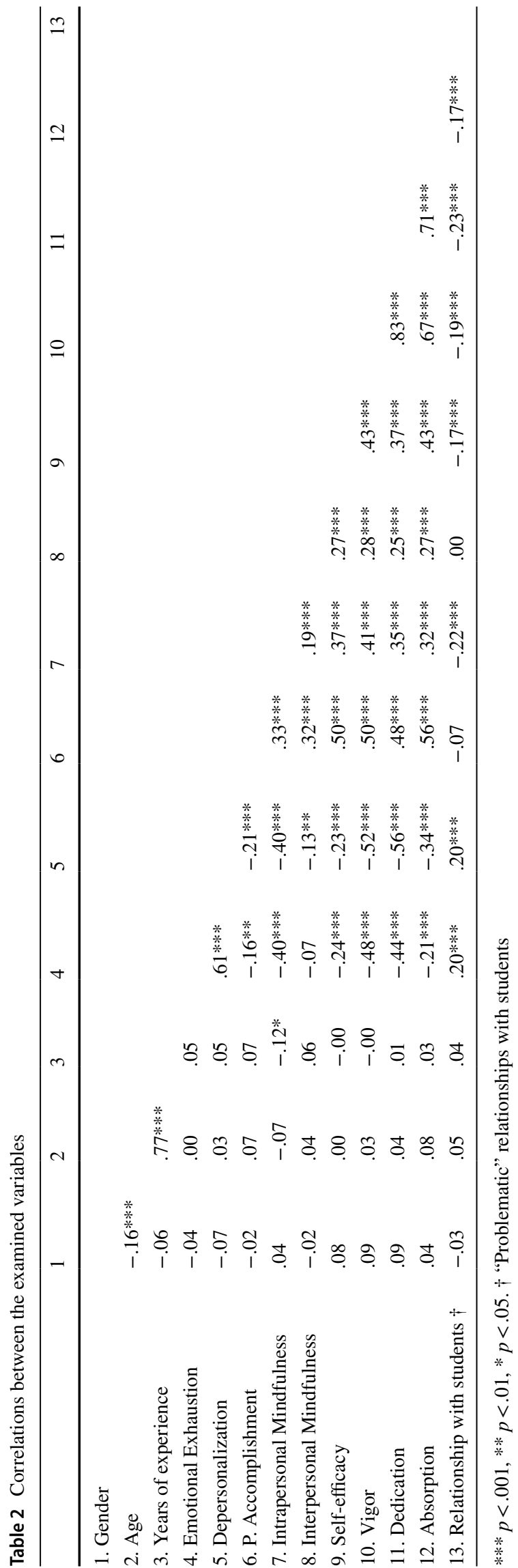

relationships with students, and between interpersonal mindfulness and relationships with students. Except for the aforementioned exception, higher levels of emotional exhaustion and depersonalization were related to less mindfulness, as well as less self-efficacy, less engagement and worse relationships with students. Higher personal accomplishment scores were related to greater mindfulness, self-efficacy and engagement, and better relationships with students. Both intrapersonal and interpersonal mindfulness were significantly correlated between them, and they were associated with a greater feeling of self-efficacy. Only the intrapersonal facet of mindfulness was significantly related to better relationships with students. Finally, there were positive correlations between engagement, mindfulness, and self-efficacy, while engagement and self-efficacy were related to better relationships with students.

The SEM model for predicting the burnout dimensions can be seen in Fig. 1, which illustrates all the significant standardized estimates and explained variance. As Fig. 1 depicts, the relation between self-efficacy and personal accomplishment follows both, a direct and indirect path mediated by interpersonal mindfulness. However, selfefficacy only had indirect effects on emotional exhaustion and depersonalization through the effects of intrapersonal mindfulness. Relationship with students predicted emotional exhaustion and depersonalization by the mediating role of intrapersonal mindfulness. That is, the better the relationships, the greater the intrapersonal mindfulness which leads to lower levels of exhaustion and depersonalization. On the other hand, years of experience was negatively related to intrapersonal mindfulness, while had a positive association with interpersonal mindfulness. Gender only was relevant for interpersonal mindfulness, indicating that men were those with a better level of interpersonal mindfulness. Only intrapersonal mindfulness was related to the burnout dimensions of emotional exhaustion and depersonalization, while interpersonal mindfulness had a positive and significant relationship with personal accomplishment. The model fit of the burnout structural model was adequate, with the following values: $\chi^{2}=2821.58 ; d f=1718 ; \chi^{2} / d f=1.64$; RMSEA $(90 \% \mathrm{CI})=0.04(0.03-0.04) ; \mathrm{SRMR}=0.06 ; \mathrm{CFI}=0.91$; TLI $=0.90$.

As Fig. 2 depicts, in the prediction of the dimensions of engagement, a negative relationship between teachersstudents had both a direct and an indirect effect on dedication, as it led to lower intrapersonal mindfulness but also to lower dedication. Self-efficacy had a direct positive effect on all three dimensions of engagement, that is, vigor, dedication and absorption, and also a mediated effect through both intrapersonal and interpersonal mindfulness. Similarly, to the previous model, experience was negatively related to intrapersonal mindfulness, while had a positive association with interpersonal mindfulness, and gender only was 


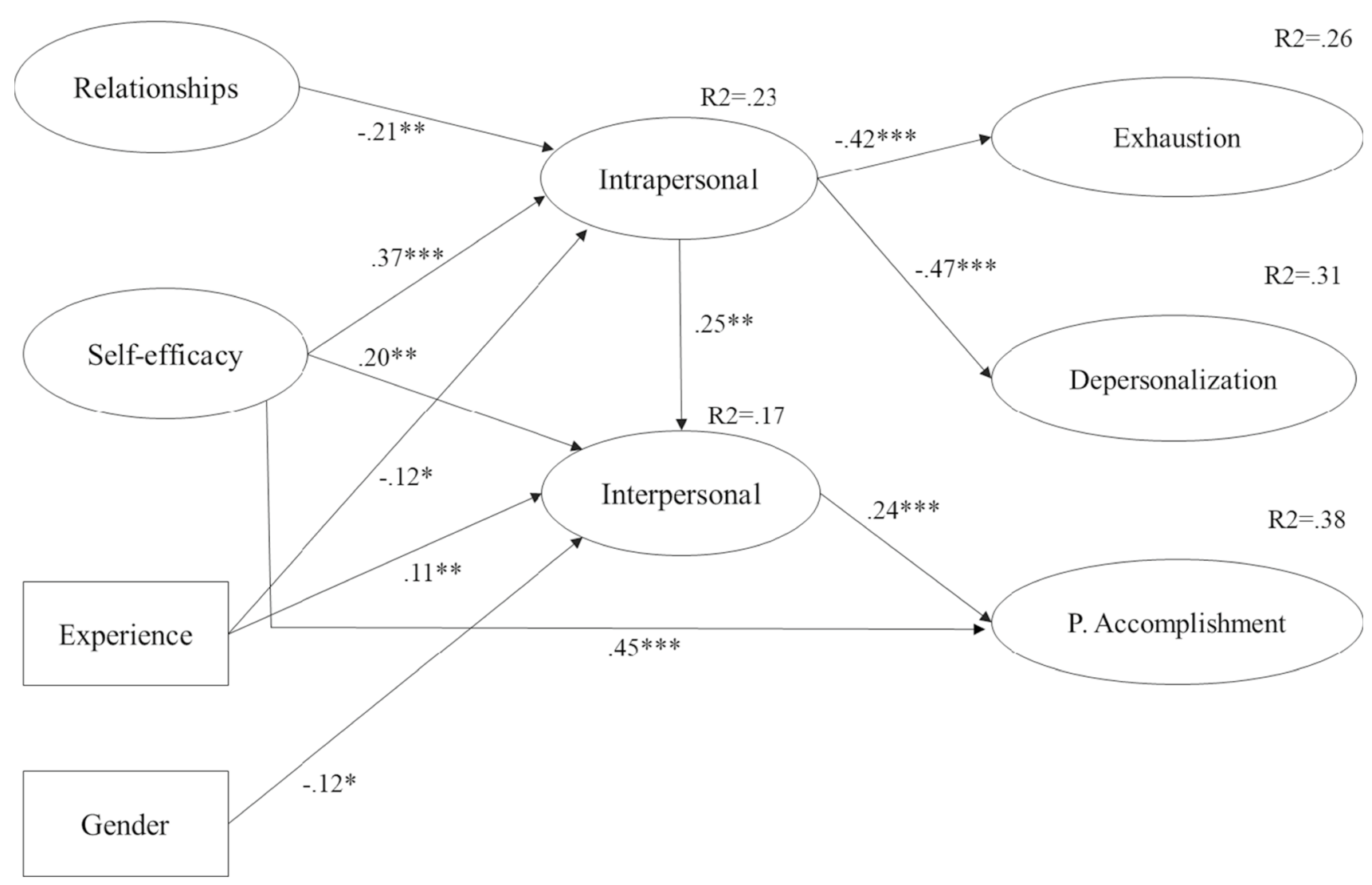

Fig. 1 Structural equation model (SEM) for the burnout dimensions. *** $p<.001 * * p<.01 * p<.05$

relevant for interpersonal mindfulness, indicating that men were those with a better level of interpersonal mindfulness. While intrapersonal mindfulness was yielded significant for vigor and dedication, interpersonal mindfulness emerged as relevant for dedication and absorption. The model fit of the engagement structural model was adequate, with the following values: $\chi^{2}=2292.48 ; d f=1326 ; \chi^{2} / d f=1.64$; RMSEA $(90 \% \mathrm{CI})=0.04(0.04-0.05) ; \mathrm{SRMR}=0.06 ; \mathrm{CFI}=0.91$; $\mathrm{TLI}=0.90$.

In summary, results indicated that both types of mindfulness emerge as significant potential mediators among relationships with students, self-efficacy, years of experience and gender with the dimensions of burnout and engagement. Age was not significantly related to any of the psychological variables. On the other hand, a relationship between intrapersonal and interpersonal mindfulness was observed, indicating that greater levels of intrapersonal mindfulness might lead to greater levels of interpersonal mindfulness. It is noteworthy to mention that, while both intrapersonal and interpersonal facets of mindfulness had a relevant mediating role for predicting the negative dimensions of burnout (i.e., emotional exhaustion, and depersonalization), their potential mediating role, although significant, seemed to be less prominent in the prediction of personal accomplishment and the engagement components, where direct associations from self-efficacy were observed.

\section{Discussion}

The main objective of the present study was to analyze the potential mediating role of mindfulness, as measured by its intrapersonal and interpersonal dimensions, in the relation between teacher's self-efficacy and teacher-student relationships, with burnout as well as engagement, in a sample of Spanish teachers. Our findings indicated (1) that teachers' levels of burnout were relatively low. Instead, the teachers in our sample showed adequate levels of mindfulness, selfefficacy, engagement and teacher-student relationships; (2) positive associations among self-efficacy, relationship with students, levels of mindfulness and engagement, and negative associations with burnout; (3) a potential mediational role of mindfulness between self-efficacy and relationship with students, and all the corresponding dimensions of burnout and engagement.

When exploring the potential mediational role of mindfulness in burnout, we found that both intrapersonal and interpersonal mindfulness types were predicted by 


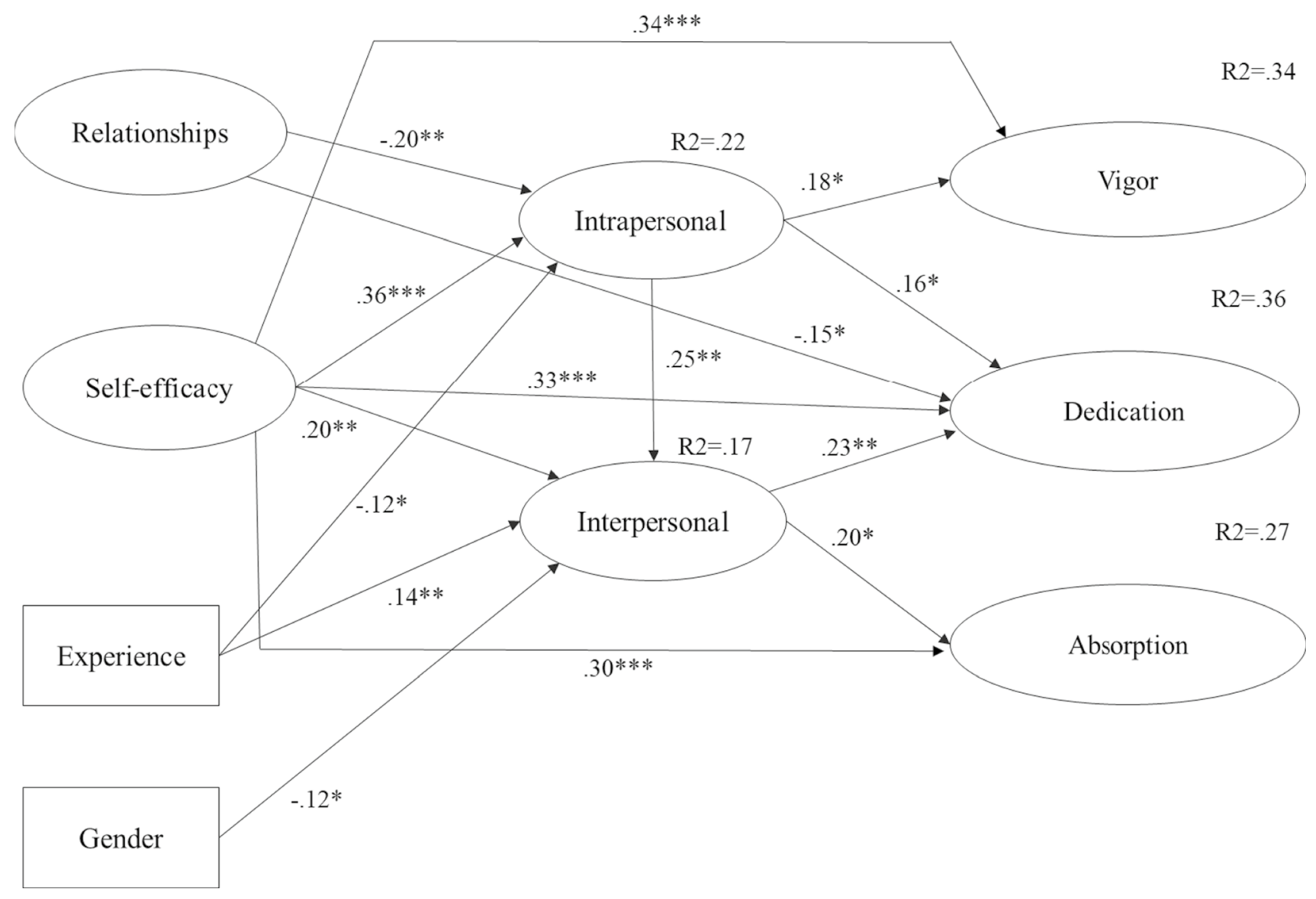

Fig. 2 Structural equation model (SEM) for the engagement dimensions. $* * * p<.001 * * p<.01 * p<.05$

self-efficacy, while only intrapersonal mindfulness was predicted by relationships with students. In addition, a significant path appeared between intrapersonal mindfulness and emotional exhaustion and depersonalization, and between interpersonal mindfulness and personal accomplishment. These findings are aligned with previous evidence for which mindfulness training for teachers has been proven efficacious in reducing occupational stress and burnout, anxiety and depressive symptoms, and in improving well-being, classroom organization, focused attention, mindfulness, and self-compassion, among others (Braun 2019; Emerson et al. 2017; Flook et al. 2013; Gold et al. 2010; Hue and Lau 2015; Molloy Elreda et al. 2019; Montero-Marin et al. 2021; Roeser et al. 2013). Relationships with others have proved to be relevant for emotional exhaustion in several workplaces, which emphasizes this social aspect as a fundamental psychological need to cope with burnout (Meng et al., 2019). According to our results, this association between relationships with others and burnout could be mediated by intrapersonal mindfulness. We have also observed a significant direct and positive path between self-efficacy and personal accomplishment. It seems that self-efficacy, by being related to individual's competence, has more to do with personal accomplishment, and the feeling of teachers' fulfillment by their job (Bang \& Reio, 2017).

Years of experience was relevant for intrapersonal and interpersonal mindfulness. We observed that teachers with greater experience are more likely to activate their "automatic pilot" and therefore are not as focused as those who are in their first years of teaching. Previous studies have shown that, as more experience we have in our daily activity or job, our levels of awareness decrease, as job becomes being a routine (Bierwolf \& Frijns, 2019). In contrast, we have also observed that those teachers with greater experience might be more fluid and aware of their relationships with students. Huang et al. (2020) found that increased teaching experience was related to a decreasing trend of empathic concern and perspective taking, and to an increasing trend of personal distress, all together suggesting that years of teaching experience might entail both risk and protective factors for individuals' mental health, and they could be independent of the effect of age, as we have also observed in the present study. Finally, we found that being men would lead to higher levels of interpersonal mindfulness. This finding contradicts previous research that has indicated that women rate themselves 
higher in interpersonal and emotional aspects, such as empathy, than men (Löffler and Greitemeyer, 2021).

An increasingly important factor in the teaching sphere is engagement (Perera et al. 2018). In our study, both intrapersonal and interpersonal mindfulness played a significant role in the prediction of engagement. However, their impact on it was lower than for burnout, as self-efficacy draws direct paths to all three dimensions of engagement - as in the case of personal accomplishment - indicating that self-efficacy could be an important predictor of these positive dimensions, while would also have indirect effects through mindfulness. As hypothesized, self-efficacy played a relevant role in predicting mindfulness, but also in predicting personal accomplishment and engagement. Self-efficacy has been extensively associated with lower burnout levels (Aloe et al. 2014; Betoret 2006; Brouwers and Tomic 2000; Friedman 2003; Schwarzer and Hallum 2008; Skaalvik and Skaalvik 2007, 2010; Wang et al. 2015), and has also been associated with engagement (Skaalvik and Skaalvik, 2014, 2016). Teachers' self-efficacy, or the beliefs that they are effective teachers, is an enhancer of actual teachers' efficacy (Klassen and Tze 2014; Meijer and Foster 1994; Skaalvik and Skaalvik 2007). Given the relevance of self-efficacy in predicting several teaching positive outcomes, it is important to understand which factors underlie this relation. However, their specific mechanisms still remain unknown (Skaalvik and Skaalvik 2017). Self-efficacy has been shown to be related to mindfulness in several studies (Byrne et al. 2014; Chang et al. 2004; Fallah 2017; Greason and Cashwell 2009; Hosseinzadeh et al., 2019; Keye and Pidgeon 2013), and our study provides further evidence for the potential mediating role of mindfulness.

Besides the direct paths of self-efficacy, engagement was also predicted by self-efficacy and teacher-student relationships by means of the mediating effect of interpersonal and intrapersonal mindfulness. However, while vigor was only predicted by intrapersonal mindfulness, dedication was predicted by both intrapersonal and interpersonal mindfulness, and absorption was predicted by interpersonal mindfulness only. These findings need to be interpreted by considering that engagement has been related to mindfulness, self-efficacy and teacher-student relationships in a variety of settings (Alessandri et al. 2015; Christenson et al. 2012; Kennedy 2010; Lee 2012; Leroy et al. 2013; Llorens-Gumbau and Salanova-Soria 2014; Luthans and Peterson 2002; Malinowski and Lim 2015; Reid 2011; Roorda et al. 2011). Interestingly, both intrapersonal and interpersonal mindfulness play a prominent role to dedication, a relevant aspect for teachers' engagement, in which emotional aspects are important for better developing their job (Pratscher et al. 2018). The fact that vigor was associated with intrapersonal mindfulness is not new in the scientific literature (Dane and Brummel, 2014; Kaçay et al. 2020; Klatt et al. 2015; Koncz et al. 2016), considering that mindfulness has traditionally consisted in the intrapersonal dimension of mindfulness (Frank et al. 2016). To the best of our knowledge, our study is novel in finding a relationship between mindfulness and absorption by considering the interpersonal facet. On the other hand, we found no significant relationships between interpersonal mindfulness and vigor, and this was also the case for exhaustion, which is the opposite to vigor (Schaufeli and Bakker 2004). Thus, mindfulness may improve vigor through attentional (intrapersonal) training which may not impact the quality of being absorbed (Koncz et al. 2016), but this quality might be affected by individuals with (interpersonal) power of reflection and empathy who can understand others' emotions and arrange their own mood accordingly (Kaçay et al. 2020).

Many studies have examined the role of teacher-student relationships for children's developmental processes. Much less is known, however, about how these relationships impact teachers' professional and personal lives (Spilt et al. 2011). Previous research has emphasized that teacherstudent relationships are appropriate for good student outcomes, which are characterized by a high teacher influence and proximity toward students (Wubbels and Brekelmans 2005). It seems obvious that the formation of personal and supportive teacher-student relationships inherently demands teachers' emotional involvement, which is one of the most agreed predictors of teachers' stress and burnout (Spilt et al. 2011).

Our findings differ from those of Frank et al.'s study (2016), in which interpersonal mindfulness predicted scores on teacher burnout, whereas intrapersonal mindfulness failed to predict burnout, suggesting that intrapersonal mindfulness may play a more important role in instructional tasks that require paying considerable attention and frequent task switching, while interpersonal mindfulness may be a more important aspect in helping teachers to develop professional efficacy. In line with this, we have observed that interpersonal mindfulness might be linked to personal accomplishment. Nevertheless, interpersonal mindfulness has also been associated with dispositional mindfulness, which is supposed to focus on intrapersonal mindfulness (Kim and Singh 2018). According to these authors, individuals with higher dispositional mindfulness levels had more emotionally supportive classrooms, were more likely to engage in perspective taking and were more sensitive to discipline. This might explain the significant link that we also observed between intrapersonal and interpersonal mindfulness. In general, our findings suggest that both intrapersonal and interpersonal mindfulness are constructs that can play an important role in teachers' burnout and engagement.

Our study adds value to the role of mindfulness as a mediator between self-efficacy, relationships with students, burnout and engagement. To our knowledge, there are no 
scientific studies in the educational field that support the potential mediating role of mindfulness in the indicated variables. The results herein obtained could be instrument dependent, because a specific tool was used to measure mindfulness in teachers, the Mindfulness in Teaching Scale (MTS). Nevertheless, other studies conducted in the workplace show that, mindfulness can act as a mediator to improve burnout (Kotzé \& Nel, 2016) or engagement (Merdiaty \& Aldrin, 2020). Therefore, our study yields novel and interesting results to be explored in future research.

Our findings have several implications in the educational field, such as promoting mindfulness training as a way to enhance teachers" "habits of mind" (Roeser et al. 2012) and thus, their occupational health, well-being and capacities to create and sustain both supportive relationships with students and classroom climates that lead to student learning. Our study is novel in that it found a relation between teacherstudent relationships and mindfulness. Listening and paying full attention to others with acceptance, and present-centered awareness of emotions along with self-regulation (i.e., low emotional and behavioral reactivity and low automaticity), can help teachers to be more responsive to individual needs and to manage challenging behavior (Frank et al. 2016). One major distinction lies in compassion (a core concept of mindfulness) and empathy. While experiencing compassion one experiences a feeling of care and concern for a person, empathy involves sharing a feeling with them and engaging with a person who is suffering, which could lead to emotional exhaustion (Klimecki et al. 2013). Given the importance of teacher-student relationships for students, and not only directly, but also due to the impact on teachers' well-being, intervention programs that specifically address teachers, and are based on the mindfulness core concept of compassion, seem a promising avenue. Finally, by differentiating between intrapersonal and interpersonal mindfulness, our results suggest that traditional mindfulness training programs based on intrapersonal mindfulness (Frank et al., 2016) could be benefitted from the novel concept of interpersonal mindfulness in the management of burnout and engagement. Thus, teacher training programs that integrate both dimensions should be created, with special attention to the benefits obtained in each of them. This allows us to predict positive results and deal with the specific needs of teachers and schools. However, further research should assess this relations (Gördesli et al. 2019; Kim and Singh 2018; Li et al. 2019).

This study has limitations. First, causal inferences are not possible because this study had a cross-sectional design. Furthermore, our results cannot guarantee the generalization to the Spanish teachers' population because no random sampling was conducted. In addition, our study was only based on selfreport measures of mindfulness, which have also some limitations. However, the present results contribute to a better understanding of the factors that can allow to better tackle the burden of teacher burnout with potential effects on student outcomes. Mindfulness, self-efficacy and teacher-student relationships have proven to be good predictors of burnout, and also engagement, which is characterized by workers who are full of energy, strongly involved in their work, and fully concentrated and happily engrossed in work activities (Bakker and Schaufeli 2015). We propose that cultivating the intrapersonal and interpersonal facets of mindfulness through targeted teacher training should be explored as a potential way to alleviate teacher's suffering.

Our study distinguishes between the emerging concepts of intrapersonal (mindfulness directed toward one's own experience) and interpersonal (one's awareness and behavior toward others) mindfulness, which enriches previous findings because former studies have more often focused on assessing the intrapersonal facet of mindfulness only (Frank et al. 2016).

Acknowledgements This research was funded in whole, or in part, by the Wellcome Trust [WT104908/Z/14/Z and WT107496/Z/15/Z]. For the purpose of open access, the authors have applied a CC BY public copyright license to any Author Accepted Manuscript version arising from this submission.

Funding Open Access funding provided thanks to the CRUE-CSIC agreement with Springer Nature. JM-M was supported by the Wellcome Trust Grant [WT104908/Z/14/Z and WT107496/Z/15/Z].

Data availability The datasets generated during and/or analysed during the current study are available from the corresponding author on reasonable request.

\section{Declarations}

Conflicts of interest/Competing interests The authors declare that they have no conflict of interest.

Ethics approval The research was approved by the Research Ethics Committee of the Spanish Autonomous Community of Aragon: CEICA (No. 08/2019; April 24, 2019). This committee is in charge of evaluating all research projects with people or personal data from the University of Zaragoza.

Consent to participate Informed consent was obtained from all individual participants included in the study.

Consent for publication Not applicable.

Open Access This article is licensed under a Creative Commons Attribution 4.0 International License, which permits use, sharing, adaptation, distribution and reproduction in any medium or format, as long as you give appropriate credit to the original author(s) and the source, provide a link to the Creative Commons licence, and indicate if changes were made. The images or other third party material in this article are included in the article's Creative Commons licence, unless indicated otherwise in a credit line to the material. If material is not included in the article's Creative Commons licence and your intended use is not permitted by statutory regulation or exceeds the permitted use, you will need to obtain permission directly from the copyright holder. To view a copy of this licence, visit http://creativecommons.org/licenses/by/4.0/. 


\section{References}

Abenavoli, R. M., Jennings, P. A., Greenberg, M. T., Harris, A. R., \& Katz, D. A. (2013). Against burnout among educators. The Pyschology of Education Review, 37(2), 57-69.

Aldrup, K., Klusmann, U., Lüdtke, O., Göllner, R., \& Trautwein, U. (2018). Student misbehavior and teacher well-being: Testing the mediating role of the teacher-student relationship. Learning and Instruction, 58(June), 126-136. https://doi.org/10.1016/j.learn instruc.2018.05.006

Alessandri, G., Borgogni, L., Schaufeli, W. B., Caprara, G. V., \& Consiglio, C. (2015). From positive orientation to job performance: The role of work engagement and self-efficacy beliefs. Journal of Happiness Studies, 16(3), 767-788. https://doi.org/10.1007/ s10902-014-9533-4

Allinder, R. M. (1994). The relationship between efficacy and the instructional practices of special education teachers and consultants. Teacher Education and Special Education: The Journal of the Teacher Education Division of the Council for Exceptional Children, 17(2), 86-95. https://doi.org/10.1177/ 088840649401700203

Aloe, A. M., Amo, L. C., \& Shanahan, M. E. (2014). Classroom management self-efficacy and burnout: A multivariate Metaanalysis. Educational Psychology Review, 26(1), 101-126. https://doi.org/10.1007/s10648-013-9244-0

Arias, F., \& González, M. E. (2009). Reinserción Laboral. Estrés, Agotamiento Profesional (Burnout) y Salud En Profesores de Acuerdo a Su Tipo de Contrato, 11(33).

Baker, J. A., Grant, S., \& Morlock, L. (2008). The teacher-student relationship as a developmental context for children with internalizing or externalizing behavior problems. School Psychology Quarterly, 23(1), 3-15. https://doi.org/10.1037/1045-3830. 23.1.3

Bakker, A. B., \& Demerouti, E. (2007). The job demands-resources model: State of the art. Journal of Managerial Psychology, 22(3), 309-328. https://doi.org/10.1108/02683940710733115

Bakker, A. B., \& Schaufeli, W. B. (2015). Work Engagement. In Wiley encyclopedia of management (pp. 1-5). John Wiley \& Sons, Ltd. https://doi.org/10.1002/9781118785317.weom110009.

Bang, H., \& Reio, T. G. (2017). Personal accomplishment, mentoring, and creative self-efficacy as predictors of creative work involvement: The moderating role of positive and negative affect. Journal of Psychology: Interdisciplinary and Applied, 151(2), 148-170. https://doi.org/10.1080/00223980.2016.1248808

Betoret, F. D. (2006). Stressors, self-efficacy, coping resources, and burnout among secondary school teachers in Spain. Educational Psychology, 26(4), 519-539. https://doi.org/10.1080/01443 410500342492

Bierwolf, R., \& Frijns, P. (2019). Consciousness, competence, and organizational change. IEEE Engineering Management Review, 47(4), 32-38.

Braun, S. S. (2019). Middle school teachers' mindfulness, Occupational Health and Well-Being, and the Quality of Teacher-Student Interactions. 245-255.

Brouwers, A., \& Tomic, W. (2000). A longitudinal study of teacher burnout and perceived self-efficacy in classroom management. Teaching and Teacher Education, 16(2), 239-253. https://doi. org/10.1016/S0742-051X(99)00057-8

Burgueño, Sicilia, \& Medina-Casaubón. (2018). Psychometry of the Teacher's sense of efficacy scale in Spanish teachers' education. The Journal of Experimental Education, 87(1), 89-100. https:// doi.org/10.1080/00220973.2018.1423542

Byrne, J., Hauck, Y., Fisher, C., Bayes, S., \& Schutze, R. (2014). Effectiveness of a mindfulness-based childbirth education pilot study on maternal self-efficacy and fear of childbirth. Journal of
Midwifery and Women's Health, 59(2), 192-197. https://doi.org/ 10.1111/jmwh.12075

Calvete, E. (2010). El estrés en profesores. Crítica.

Caprara, G. V., Barbaranelli, C., Borgogni, L., \& Steca, P. (2003). Efficacy beliefs as determinants of teachers' job satisfaction. Psycnet.Apa.Org. https://psycnet.apa.org/record/2003-09576014. Accessed 20 May 2020.

Chang, V. Y., Palesh, O., Caldwell, R., Glasgow, N., Abramson, M., Luskin, F., Gill, M., Burke, A., \& Koopman, C. (2004). The effects of a mindfulness-based stress reduction program on stress, mindfulness self-efficacy, and positive states of mind. Stress and Health, 20(3), 141-147. https://doi.org/10.1002/smi.1011

Christenson, S. L., Wylie, C., \& Reschly, A. L. (2012). Handbook of research on student engagement. Handbook of Research on Student Engagement., 1-840. https://doi.org/10.1007/ 978-1-4614-2018-7

Coladarci, T. (1992). Teachers' sense of efficacy and commitment to teaching. Journal of Experimental Education, 60(4), 323-337. https://doi.org/10.1080/00220973.1992.9943869

Corbin, C. M., Alamos, P., Lowenstein, A. E., Downer, J. T., \& Brown, J. L. (2019). The role of teacher-student relationships in predicting teachers' personal accomplishment and emotional exhaustion. Journal of School Psychology, 77(October), 1-12. https:// doi.org/10.1016/j.jsp.2019.10.001

Cornelius-White, J. (2007). Learner-centered teacher-student relationships are effective: A meta-analysis. Review of Educational Research, 77(1), 113-143. https://doi.org/10.3102/0034654302 98563

Dane, E., \& Brummel, B. J. (2014). Examining workplace mindfulness and its relations to job performance and turnover intention. Human Relations, 67(1), 105-128. https://doi.org/10.1177/00187 26713487753

Demerouti, E. , Nachreiner, F., Bakker, A.B., \& Schaufeli, W. B. (2001). Articles_Arnold_Bakker_69.Pdf. In Journal of Applied Psychology (Vol. 86, issue 3, pp. 499-512).

Díaz, F., López, A., \& Varela, M. T. (2012). Factors associated to burnout syndrome in high school teachers in Cali, Colombia. Universitas Psychologica, 11(1), 217-227 http://www.scielo.org.co/ scielo.php?script=sci_arttext\&pid=S1657-92672012000100018

Díaz-Aguado Jalón, M. J., Martínez Arias, R., \& Martín Babarro, J. (2013). El acoso entre adolescentes en España1. Prevalencia, papeles adoptados por todo el grupo y características a las que atribuyen la victimización. Revista de Educacion, 362, 348-379. https://doi.org/10.4438/1988-592X-RE-2011-362-164

Durán, M. A., Extremera, N., Montalbán, F. M. y Rey, L. (2005). Engagement y Burnout en el ámbito docente: Análisis de sus relaciones con la satisfacción laboral y vital en una muestra de profesores. Revista de Psicología Del Trabajo y de Las Organizaciones, 21(1-2), 145-158.

Emerson, L. M., Leyland, A., Hudson, K., Rowse, G., Hanley, P., \& Hugh-Jones, S. (2017). Teaching mindfulness to teachers: a systematic review and narrative synthesis. Mindfulness, 8(5), 1136-1149. https://doi.org/10.1007/s12671-017-0691-4

Esteras, J., Chorot, P., \& Sandín, B. (2014). Predicción del burnout en los docentes: Papel de los factores organizacionales, personales y sociodemográficos. Revista de Psicopatologia y Psicologia Clinica, 19(2), 79-92. https://doi.org/10.5944/rppc.vol.19.num.2. 2014.13059

Evers, W. J. G., Brouwers, A., \& Tomic, W. (2002). Burnout and selfefficacy: A study on teachers' beliefs when implementing an innovative educational system in the Netherlands. British Journal of Educational Psychology, 72(2), 227-243. https://doi.org/10. 1348/000709902158865

Fallah, N. (2017). Mindfulness, coping self-efficacy and foreign language anxiety: a mediation analysis. Educational Psychology, 37(6), 745-756. https://doi.org/10.1080/01443410.2016.1149549 
Flook, L., Goldberg, S. B., Pinger, L., Bonus, K., \& Davidson, R. J. (2013). Mindfulness for teachers: A pilot study to assess effects on stress, burnout, and teaching efficacy. Mind, Brain, and Education, 7(3), 182-195. https://doi.org/10.1111/mbe.12026

Frank, J. L., Jennings, P. A., \& Greenberg, M. T. (2016). Validation of the mindfulness in teaching scale. Mindfulness, 7(1), 155-163. https://doi.org/10.1007/s12671-015-0461-0

Friedman, I. A. (2003). Self-efficacy and burnout in teaching: The importance of interpersonal-relations efficacy. Social Psychology of Education, 6(3), 191-215. https://doi.org/10.1023/A: 1024723124467

Gantiva, C. A., Jaimes, S., \& Villa, M. C. (2010). Síndrome de Burnout y Estrategias de Afrontamiento en Docentes Universitarios. Revista Iberoamericana de Psicología: Ciencia y Tecnología, 2(1), 21-30. https://doi.org/10.33881/2027-1786.rip.\%x

García-Carmona, M., Marín, M. D., \& Aguayo, R. (2019). Burnout syndrome in secondary school teachers: a systematic review and meta-analysis. Social Psychology of Education, 22(1), 189-208. https://doi.org/10.1007/s11218-018-9471-9

Gold, E., Smith, A., Hopper, I., Herne, D., Tansey, G., \& Hulland, C. (2010). Mindfulness-based stress reduction (MBSR) for primary school teachers. Journal of Child and Family Studies, 19(2), 184-189. https://doi.org/10.1007/s10826-009-9344-0

Gördesli, M. A., Arslan, R., Çekici, F., Sünbül, Z. A., \& Malkoç, A. (2019). The psychometric properties of the mindfulness in teaching scale in a Turkish sample. Universal Journal of Educational Research, 7(2), 381-386. https://doi.org/10.13189/ ujer.2019.070210.

Greason, P. B., \& Cashwell, C. S. (2009). Counselor preparation mindfulness and counseling self-efficacy: The mediating role of attention and empathy. Counselor Education and Supervision, 49(1), 2-19. https://doi.org/10.1002/j.1556-6978.2009. tb00083.x

Guerrero, E., Gomez, R., Moreno, J. M., Garcia-Baamonde, E., \& Blazquez, M. (2011). El síndrome del quemado, modos de afrontamiento del estrés y salud mental en profesores no universitarios. Search.Proquest.Com. http://search.proquest.com/openv iew/b85d21 ca2a66da4e8bb515994c5bd2f6/1 ?pq-origsite=gscho lar\&cbl=966333\&casa_token $=$ lfd6U42R1FUAAAAA:KBJWc C8AnYXBGOyW0_sy2LRPcWN4ocs7B mj1VRJI4_n5II6 PQCKXhbjyKMaU2ZGs07azMYTD. Accessed 20 May 2020.

Heineberg, B. D. L. (2016). Promoting caring: Mindfulness- and compassion-based contemplative training for educators and students (pp. 285-294). https://doi.org/10.1007/978-1-4939-3506-2_18.

Hu, L. T., \& Bentler, P. M. (1999). Cutoff criteria for fit indexes in covariance structure analysis: Conventional criteria versus new alternatives. Structural Equation Modeling, 6(1), 1-55. https:// doi.org/10.1080/10705519909540118

Huang, L., Zhang, T., Evaluation, Y. H.-S., \& in E., \& 2020, U. (2020). Effects of school organizational conditions on teacher professional learning in China: The mediating role of teacher selfefficacy. Studies in Educational Evaluation. https://www.scien cedirect.com/science/article/pii/S0191491X20301413?casa_ token=vPTJ8PmJQSIAAAAA:eZyZzRmsuPC7Zcxb6b6bwyq7 RQ8Xe61k0oEZeKOAhd2Gmwngi5BncYeDozzfQBla-1pXTC mVVY

Hue, M. T., \& Lau, N. S. (2015). Promoting well-being and preventing burnout in teacher education: a pilot study of a mindfulness-based programme for pre-service teachers in Hong Kong. Teacher Development, 19(3), 381-401. https://doi.org/10.1080/ 13664530.2015.1049748

Hughes, J. N., Cavell, T. A., \& Willson, V. (2001). Further support for the developmental significance of the quality of the teacher - student relationship. Journal of School Psychology, 39(4), 289-301. https://doi.org/10.1016/S0022-4405(01)00074-7
Judge, T. A., Bono, J. E., Thoresen, C. J., \& Patton, G. K. (2001). The job satisfaction-job performance relationship: A qualitative and quantitative review. Psychological Bulletin, 127(3), 376-402. https://doi.org/10.1037//0033-2909.127.3.376

Kabat-Zinn. (1994). Wherever you go, there you are: Mindfulness meditation in everyday life. Hyperion.

Kaçay, Z., Güngör, N. B., Yenel, F., \& Soyer, F. (2020). The effect of work engagement and mindfulness on organizational behavior. Journal of Educational Issues, 6(2), 478. https://doi.org/10.5296/ jei.v6i2.17975

Kennedy, E. (2010). Narrowing the achievement gap: Motivation, engagement, and self-efficacy matter. Journal of Education, 190(3), 1-11. https://doi.org/10.1177/002205741019000302

Keye, M. D., \& Pidgeon, A. M. (2013). Investigation of the relationship between resilience, mindfulness, and academic self-efficacy. Open Journal of Social Sciences, 01(06), 1-4. https://doi.org/10. 4236/jss.2013.16001

Kim, E., \& Singh, N. N. (2018). Psychometric properties of the Korean version of the mindfulness in teaching scale. Mindfulness, 9(1), 344-351. https://doi.org/10.1007/s12671-017-0871-2

Kim, L., Jörg, V., \& Klassen, R. (2019). A meta-analysis of the effects of teacher personality on teacher effectiveness and burnout. https://link.springer.com/article/10.1007/s10648-018-9458-2

Klassen, R. M., \& Tze, V. M. C. (2014). Teachers' self-efficacy, personality, and teaching effectiveness: A meta-analysis. Educational Research Review, 12, 59-76. https://doi.org/10.1016/j. edurev.2014.06.001

Klatt, M., Steinberg, B., \& Duchemin, A. M. (2015). Mindfulness in motion (Mim): An onsite mindfulness based intervention (mbi) for chronically high stress work environments to increase resiliency and work engagement. Journal of Visualized Experiments, 2015(101), 1-11. https://doi.org/10.3791/52359

Klimecki, O. M., Leiberg, S., Ricard, M., \& Singer, T. (2013). Differential pattern of functional brain plasticity after compassion and empathy training. Social Cognitive and Affective Neuroscience, 9(6), 873-879. https://doi.org/10.1093/scan/nst060

Koncz, R., Wolfenden, F., Hassed, C., Chambers, R., Cohen, J., \& Glozier, N. (2016). Mindfulness-based stress release program for university employees a pilot, waitlist-controlled trial and implementation replication. Journal of Occupational and Environmental Medicine, 58(10), 1021-1027. https://doi.org/ 10.1097/JOM.0000000000000856

Kotzé, M., \& Nel, P. (2016). The psychometric properties of the mindful attention awareness scale (MAAS) and Freiburg mindfulness inventory (FMI) as measures of mindfulness and their relationship with burnout and work engagement. SA Journal of Industrial Psychology. http://www.scielo.org.za/scielo.php? pid=S2071-07632016000100025\&script=sci_arttext\&tlng=es

Küster, I., \& Vila, N. (2012). El docente universitario y sus efectos en el estudiante. Estudios Sobre Educación.

Kyriacou, C. (2001). Teacher stress: Directions for future research. Educational Review, 53(1), 27-35. https://doi.org/10.1080/ 00131910120033628

Lazarus, R. S., \& Folkman, S. (1984). Stress, appraisal, and coping. Springer publishing company.

Lee, J. S. (2012). The effects of the teacher-student relationship and academic press on student engagement and academic performance. International Journal of Educational Research, 53, 330-340. https://doi.org/10.1016/j.ijer.2012.04.006

Leiter, M., \& Maslach, C. (1998). Burnout. In E. H. Friedman (Ed.), Encyclopedia of Mental Health.

Leroy, H., Anseel, F., Dimitrova, N. G., \& Sels, L. (2013). Mindfulness, authentic functioning, and work engagement: A growth modeling approach. Journal of Vocational Behavior, 82(3), 238-247. https://doi.org/10.1016/j.jvb.2013.01.012 
Li, C., Kee, Y. H., \& Wu, Y. (2019). Psychometric properties of the chinese version of the mindfulness in teaching scale. International Journal of Environmental Research and Public Health, 16(13). https://doi.org/10.3390/ijerph16132405

Llorens-Gumbau, S., \& Salanova-Soria, M. (2014). Loss and gain cycles? A longitudinal study about burnout, engagement and self-efficacy. Burnout Research, 1(1), 3-11. https://doi.org/10. 1016/j.burn.2014.02.001

Löffler, C. S., \& Greitemeyer, T. (2021). Are women the more empathetic gender? The effects of gender role expectations. Current Psychology, Eagly. https://doi.org/10.1007/s12144-020-01260-8

López-López, I. M., Gómez-Urquiza, J. L., Cañadas, G. R., De la Fuente, E. I., Albendín-García, L., \& Cañadas-De la Fuente, G. A. (2019). Prevalence of burnout in mental health nurses and related factors: a systematic review and meta-analysis. In International journal of mental health nursing (Vol. 28, issue 5, pp. 1032-1041). Blackwell Publishing. https://doi.org/10. 1111/inm.12606.

Luthans, F., \& Peterson, S. J. (2002). Employee engagement and manager self-efficacy. Journal of Management Development, 21(5), 376-387. https://doi.org/10.1108/02621710210426864

Malinowski, P., \& Lim, H. J. (2015). Mindfulness at work: Positive affect, hope, and optimism mediate the relationship between dispositional mindfulness, work engagement, and well-being. Mindfulness, 6(6), 1250-1262. https://doi.org/10.1007/ s12671-015-0388-5

Marsh, H. W., Hau, K. T., \& Wen, Z. (2004). In search of golden rules: Comment on hypothesis-testing approaches to setting cutoff values for fit indexes and dangers in overgeneralizing $\mathrm{Hu}$ and Bentler's (1999) findings. Structural Equation Modeling, 11(3), 320-341. https://doi.org/10.1207/s15328007sem1103_2

Maslach, C., \& Jackson, S. E. (1981). The measurement of experienced burnout. Journal of Organizational Behavior, 2(2), 99-113. https://doi.org/10.1002/job.4030020205

Maslach, C, Jackson, S., \& Leiter, M. (1997). Maslach burnout inventory. https://psycnet.apa.org/record/1997-09146-011

Meijer, C. J. W., \& Foster, S. F. (1994). The effect of posture o $\mathrm{n}$ a signature. Journal of Management Studies, 31:6(November), 1974-1974.

Meiklejohn, J., Phillips, C., Freedman, M. L., Griffin, M. L., Biegel, G., Roach, A., Frank, J., Burke, C., Pinger, L., Soloway, G., Isberg, R., Sibinga, E., Grossman, L., \& Saltzman, A. (2012). Integrating mindfulness training into K-12 education: Fostering the resilience of teachers and students. In Mindfulness (Vol. 3, issue 4, pp. 291-307). https://doi.org/10.1007/s12671-012-0094-5.

Meng, H., Luo, Y., Huang, L., Wen, J., Ma, J., \& Xi, J. (2019). On the relationships of resilience with organizational commitment and burnout: a social exchange perspective. International Journal of Human Resource Management, 30(15), 2231-2250. https://doi. org/10.1080/09585192.2017.1381136

Merdiaty, N., \& Aldrin, N. (2020). Analyzing the effect of resilience on burnout with mindfulness as a mediator. International Journal of Research in Business and Social Science (2147- 4478), 9(5), 109-115. https://doi.org/10.20525/ijrbs.v9i5.820.

Milatz, A., Lüftenegger, M., \& Schober, B. (2015). Teachers' relationship closeness with students as a resource for teacher wellbeing: A response surface analytical approach. Frontiers in Psychology, 6(DEC). https://doi.org/10.3389/fpsyg.2015.01949.

Mochrie, K. D., Lothes, J., Quickel, E. J. W., St. John, J., \& Carter, C. (2019). From the hospital to the clinic: The impact of mindfulness on symptom reduction in a DBT partial hospital program. Journal of Clinical Psychology, 75(7), 1169-1178. https://doi. org/10.1002/jclp.22774

Mojsa-Kaja, J., Golonka, K., \& Marek, T. (2015). Job burnout and engagement among teachers - Worklife areas and personality traits as predictors of relationships with work. International
Journal of Occupational Medicine and Environmental Health, 28(1), 102-119. https://doi.org/10.13075/ijomeh.1896.00238.

Molloy Elreda, L., Jennings, P. A., DeMauro, A. A., Mischenko, P. P., \& Brown, J. L. (2019). Protective effects of interpersonal mindfulness for teachers' emotional supportiveness in the classroom. Mindfulness, 10(3), 537-546. https://doi.org/10.1007/ s12671-018-0996-y

Montero-Marin, J., Taylor, L., Crane, C., Greenberg, M. T., Ford, T. J., Williams, J. M. G., Garcia-Campayo, J., Sonley, A., Lord, L., Dalgleish, T., et al. (2021). Teachers 'finding peace in a frantic world': An experimental study of self-taught and instructor-led mindfulness program formats on acceptability, effectiveness and mechanisms. Journal of Educational Psychology. https://doi.org/ 10.1037/edu0000542

Moreno Jiménez, B., Garrosa Hernández, E., \& González Gutiérrez, J. L. (2000). La evaluación del estrés y el burnout del profesorado: el CBP-R. Revista de Psicología Del Trabajo y de Las Organizaciones, 16(2).

Moyano, N., Navarro-Gil, M., Pérez-Yus, M. C., Herrera-Mercadal, P., $\&$ Valle, S. (2021). Psychometric properties of the mindfulness in teaching scale among Spanish teachers. Current Psychology. https://doi.org/10.1007/s12144-021-01600-2

Napoli, M. (2004). ARTICLE M. Napoli mindfulness training for teachers mindfulness training for teachers: A pilot program. Complementary Health Practice Review, 9(1), 31-42. https:// doi.org/10.1177/1076167503253435

Organization, W. H. O.-W. H., Geneva, U., Switzerland, U., \& 2019, U. (2019). Burn-out an "occupational phenomenon": International Classification of Diseases.

Özcan, N. A., \& Vural, Ö. (2020). The mediator role of thriving in the relationship between self-efficacy and mindfulness in middleadolescence sample. Educational Sciences: Theory and Practice, 20(3), 56-66. https://doi.org/10.12738/jestp.2020.3.005.

Perera, H. N., Vosicka, L., Granziera, H., \& McIlveen, P. (2018). Towards an integrative perspective on the structure of teacher work engagement. Journal of Vocational Behavior, 108(May), 28-41. https://doi.org/10.1016/j.jvb.2018.05.006

Pratscher, S. D., Rose, A. J., Markovitz, L., \& Bettencourt, A. (2018). Interpersonal mindfulness: Investigating mindfulness in interpersonal interactions, co-rumination, and friendship quality. Mindfulness, 9(4), 1206-1215. https://doi.org/10.1007/ s12671-017-0859-y

Reid, D. (2011). Mindfulness and flow in occupational engagement: Presence in doing. Canadian Journal of Occupational Therapy, 78(1), 50-56. https://doi.org/10.2182/cjot.2011.78.1.7

Rhemtulla, M., Brosseau-Liard, P. É., \& Savalei, V. (2012). When can categorical variables be treated as continuous? A comparison of robust continuous and categorical SEM estimation methods under suboptimal conditions. Psychological Methods, 17(3), 354-373. https://doi.org/10.1037/a0029315

Roeser, R. W., Skinner, E., Beers, J., \& Jennings, P. A. (2012). Mindfulness training and teachers' professional development: An emerging area of research and practice. Child Development Perspectives, 6(2), 167-173. https://doi.org/10.1111/j.1750-8606. 2012.00238.x

Roeser, R. W., Schonert-Reichl, K. A., Jha, A., Cullen, M., Wallace, L., Wilensky, R., Oberle, E., Thomson, K., Taylor, C., \& Harrison, J. (2013). Mindfulness training and reductions in teacher stress and burnout: Results from two randomized, waitlist-control field trials. Journal of Educational Psychology, 105(3), 787-804. https://doi.org/10.1037/a0032093

Roorda, D. L., Koomen, H. M. Y., Spilt, J. L., \& Oort, F. J. (2011). The influence of affective teacher-student relationships on students' school engagement and achievement: A meta-analytic approach. Review of Educational Research, 81(4), 493-529. https://doi.org/ 10.3102/0034654311421793 
Salanova, M., Cifre, E., Grau, R. M., Llorens, S., \& Martínez, I. M. (2005). Antecedentes de la autoeficacia en profesores y estudiantes universitarios: un modelo causal. Redalyc.Org. https:// www.redalyc.org/pdf/2313/231317039010.pdf. Accessed 20 May 2020.

Savaş, A. C., Bozgeyik, Y., \& Eser, İ. (2014). A study on the relationship between teacher self efficacy and burnout. In International Journal of Environmental \& Science Education, $3 \mathrm{http}: / / \mathrm{www}$. eurojedu.com

Schaufeli, W., \& Bakker, A. (2004). UTRECHT WORK ENGAGE$M E N T$ SCALE manual (Utrecht University (ed.); issue December)

Schaufeli, W., Salanova, M., González-romá, V., \& Bakker, A. (2002). The measurement of engagement and burnout: A two sample confirmatory factor analytic approach. Journal of Happiness Studies, 3(1), 71-92. https://doi.org/10.1023/A:1015630930326

Schaufeli, W. B., Bakker, A. B., \& Salanova, M. (2006). The measurement of work engagement with a short questionnaire : A. Journals.Sagepub.Com, 66(4), 701-716. doi: https://doi.org/10.1177/ 0013164405282471 .

Schermelleh-Engel, K., Moosbrugger, H., \& Müller, H. (2003). Evaluating the fit of structural equation models: Tests of significance and descriptive goodness-of-fit measures. MPR-Online, 8(2), 23-74.

Schwarzer, R., \& Hallum, S. (2008). Perceived teacher self-efficacy as a predictor of job stress and burnout: Mediation analyses. Applied Psychology, 57(SUPPL. 1), 152-171. https://doi.org/10.1111/j. 1464-0597.2008.00359.x

Seligman, M. E. P., \& Csikszentmihalyi, M. (2014). Positive psychology: An introduction. In Flow and the foundations of positive psychology: The collected works of Mihaly Csikszentmihalyi (Vol. 9789401790888, pp. 279-298). Springer Netherlands. https://doi.org/10.1007/978-94-017-9088-8_18.

Shoji, K., Cieslak, R., Smoktunowicz, E., Rogala, A., Benight, C. C., \& Luszczynska, A. (2016). Associations between job burnout and self-efficacy: A meta-analysis. Anxiety, Stress and Coping, 29(4), 367-386. https://doi.org/10.1080/10615806.2015.1058369

Skaalvik, E. M., \& Skaalvik, S. (2007). Dimensions of teacher selfefficacy and relations with strain factors, perceived collective teacher efficacy, and teacher burnout. Journal of Educational Psychology, 99(3), 611-625. https://doi.org/10.1037/0022-0663. 99.3.611

Skaalvik, E. M., \& Skaalvik, S. (2010). Teacher self-efficacy and teacher burnout: A study of relations. Teaching and Teacher Education, 26(4), 1059-1069. https://doi.org/10.1016/j.tate. 2009.11.001

Skaalvik, E. M., \& Skaalvik, S. (2014). Teacher self-efficacy and perceived autonomy: Relations with teacher engagement, job satisfaction, and emotional exhaustion. Psychological Reports, 114(1), 68-77. https://doi.org/10.2466/14.02.PR0.114k14w0
Skaalvik, E. M., \& Skaalvik, S. (2016). Teacher stress and teacher selfefficacy as predictors of engagement, emotional exhaustion, and motivation to leave the teaching profession. Creative Education, 07(13), 1785-1799. https://doi.org/10.4236/ce.2016.713182

Skaalvik, E. M., \& Skaalvik, S. (2017). Teacher stress and teacher selfefficacy: Relations and consequences (pp. 101-125). Springer. https://doi.org/10.1007/978-3-319-53053-6_5

Spilt, J. L., Koomen, H. M. Y., \& Thijs, J. T. (2011). Teacher wellbeing: The importance of teacher-student relationships. Educational Psychology Review, 23(4), 457-477. https://doi.org/10.1007/ s10648-011-9170-y

Stein, M. K., \& Wang, M. C. (1988). Teacher development and school improvement: The process of teacher change. Elsevier. https:// www.sciencedirect.com/science/article/pii/0742051X88900169. Accessed 20 May 2020.

Tawfik, D. S., Scheid, A., Profit, J., Shanafelt, T., Trockel, M., Adair, K. C., Bryan Sexton, J., \& Ioannidis, J. P. A. (2019). Evidence relating health care provider burnout and quality of care a systematic review and meta-analysis. Annals of Internal Medicine, 171(8), 555-567. https://doi.org/10.7326/M19-1152

Taxer, J. L., Becker-Kurz, B., \& Frenzel, A. C. (2019). Do quality teacher-student relationships protect teachers from emotional exhaustion? The mediating role of enjoyment and anger. Social Psychology of Education, 22(1), 209-226. https://doi.org/10. 1007/s11218-018-9468-4

Taylor, N. Z., \& Millear, P. M. R. (2016). The contribution of mindfulness to predicting burnout in the workplace. Personality and Individual Differences, 89, 123-128. https://doi.org/10.1016/j. paid.2015.10.005

Tifner, S., Martín, P., Albanesi, S., Nasetta, D. E., \& De Bortoli, M. (2006). Burnout and teaching. In STVDIVM. Revista de Humanidades (Vol. 12). https://dialnet.unirioja.es/descarga/articulo/ 2542032.pdf

Tschannen-Moran, M., \& Hoy, A. W. (2001). Teacher efficacy: Capturing an elusive construct. Elsevier. Retrieved May 20, 2020, from https://www.sciencedirect.com/science/article/pii/S0742051X0 1000361 ?casa_token $=3$ t6QJIOv3 VcAAAAA:Gmduz603JG tJRaeniIamuo04y2PObZVNr-P9oR2i0xu2nRKmuvTxMUFt3rt mu6Cck8bZVdLD

Wang, H., Hall, N. C., \& Rahimi, S. (2015). Self-efficacy and causal attributions in teachers: Effects on burnout, job satisfaction, illness, and quitting intentions. Teaching and Teacher Education, 47, 120-130. https://doi.org/10.1016/j.tate.2014.12.005

Wubbels, T., \& Brekelmans, M. (2005). Two decades of research on teacher-student relationships in class. International Journal of Educational Research, 43(1-2), 6-24. https://doi.org/10.1016/j. ijer.2006.03.003

Publisher's note Springer Nature remains neutral with regard to jurisdictional claims in published maps and institutional affiliations. 